\title{
Effects of sex on response of the bovine preimplantation embryo to insulin-like growth factor 1, activin A, and WNT7A
}

Paula Tríbulo ${ }^{1}$, Gulnur Jumatayeva ${ }^{1,3}$, Khoboso Lehloenya $^{2}$, James I. Moss' ${ }^{1}$ Veronica M. Negrón-Pérez ${ }^{1,4}$ and Peter J. Hansen ${ }^{1 *}$ (i)

\begin{abstract}
Background: Alterations in maternal environment can sometimes affect embryonic development in a sexuallydimorphic manner. The objective was to determine whether preimplantation bovine embryos respond to three maternally-derived cell signaling molecules in a sex-dependent manner.

Results: Actions of three embryokines known to increase competence of bovine embryos to develop to the blastocyst stage, insulin-like growth factor 1 (IGF1), activin A, and WNT member 7A (WNT7A), were evaluated for actions on embryos produced in vitro with $X$ - or $Y$ - sorted semen from the same bull. Each embryokine was tested in embryos produced by in vitro fertilization of groups of oocytes with either pooled sperm from two bulls or with sperm from individual bulls. Embryos were treated with IGF1, activin A, or WNT7A on day 5 of culture. All three embryokines increased the proportion of cleaved zygotes that developed to the blastocyst stage and the effect was similar for female and male embryos. As an additional test of sexual dimorphism, effects of IGF1 on blastocyst expression of a total of 127 genes were determined by RT-qPCR using the Fluidigm Delta Gene assay. Expression of 18 genes was affected by sex, expression of 4 genes was affected by IGF1 and expression of 3 genes was affected by the IGF1 by sex interaction.

Conclusion: Sex did not alter how IGF1, activin A or WNT7A altered developmental competence to the blastocyst stage. Thus, sex-dependent differences in regulation of developmental competence of embryos by maternal regulatory signals is not a general phenomenon. The fact that sex altered how IGF1 regulates gene expression is indicative that there could be sexual dimorphism in embryokine regulation of some aspects of embryonic function other than developmental potential to become a blastocyst.
\end{abstract}

Keywords: Embryo, Sex-sorted semen, Embryokine, Insulin-like growth factor 1, Activin a, WNT7A

\section{Background}

The environment established by the mother for the preimplantation embryo plays a key role in ensuring proper development. Its importance for the fate of the embryo can be observed by examination of the consequences of embryo production in vitro, i.e., in the absence of maternal signals. Such embryos differ from their in vivo counterparts in terms of gene expression [1], metabolism [2], lipid content [3, 4], ultrastructure [5], freezability [6],

\footnotetext{
* Correspondence: pjhansen@ufl.edu

${ }^{1}$ Department of Animal Sciences, D. H. Barron Reproductive and Perinatal Biology Research Program, and Genetics Institute, University of Florida, Gainesville, PO Box 110910, Gainesville, FL 32611-0910, USA

Full list of author information is available at the end of the article
}

DNA methylation [7], competence to establish pregnancy [8] and postnatal phenotype [9-12]. One of the mechanisms by which the mother controls embryonic development involves secretion of cell signaling molecules called embryokines that modulate embryonic growth, differentiation and other aspects of embryonic function. Among the embryokines that improve development of embryos to the blastocyst stage in the cow are activin A [13], colony stimulating factor 2 (CSF2) $[14,15]$, insulin-like growth factor 1 (IGF1) [16], interleukin-1 $\beta$ [17], and WNT member 7A (WNT7A) [18].

Some alterations in the maternal environment during the periconceptional period affect developmental outcomes of

(c) The Author(s). 2018 Open Access This article is distributed under the terms of the Creative Commons Attribution 4.0 International License (http://creativecommons.org/licenses/by/4.0/), which permits unrestricted use, distribution, and 
female embryos differently than male embryos. Examples include consequences of in vitro embryo production [19] and maternal deficiency in dietary protein in mice [20], and feeding a diet deficient in vitamin $\mathrm{B}$ and methionine in sheep [21]. Sexual dimorphism in response to altered maternal function could be mediated by changes in secretion of embryokines which act on female embryos differently than male embryos. In cattle, differences in DNA methylation exist between female and male embryos as early as the 8-cell stage [22] and, by the blastocyst stage, expression of as many as one third of the expressed genes differ according to sex [23]. Experiments with CSF2 indicate that differences in cellular function between female and male embryos can lead to differential responses to cell signaling molecules. Treatment of bovine embryos with CSF2 from Day 5 to 7 of development (i.e., when the embryo transitions from the morula to blastocyst stages of development) increased the proportion of female embryos becoming blastocysts while not affecting development of male embryos [15]. Treatment of embryos with CSF2 from Day 5 to 7 also acted in a sexually-dimorphic manner to affect development subsequent to Day 15 when embryos were transferred into recipient females [24]. For female embryos, CSF2 treatment decreased trophoblast elongation and secretion of the maternal recognition of pregnancy protein, interferon- $\tau$, but opposite effects occurred in male embryos.

It is not known whether sexual dimorphism in embryonic responses to embryokines is a widespread phenomenon or occurs for a few regulatory molecules only. To address this question, the present series of experiments were performed to determine whether three embryokines exert differential effects on female and male embryos in the cow. The three molecules studied, IGF1, activin A, and WNT7A, were chosen because genes for each of the molecules are highly expressed in the bovine endometrium during the first 7 days of the estrous cycle [25] and the proteins act on the bovine embryo to increase development to the blastocyst stage in culture $[13,16,18]$.

\section{Results}

\section{Development to the blastocyst stage}

Results are shown in Fig. 1. Each of the embryokines tested increased the percent of cleaved embryos becoming a blastocyst compared to the vehicle group. This was the case for IGF1 (experiment $1, P=0.006$; experiment $2, P=$ 0.08 ), activin A (experiment $3, P=0.0002$; experiment 4 , $P=0.0028$ ) and WNT7A (experiment $5, P=0.005$; experiment $6 ; P=0.011$ ). In general, the percent of cleaved embryos becoming a blastocyst was not affected by sex. The exception was for experiment 3 in which effects of activin A were tested for embryos produced using pooled spermatozoa. In this case, a higher proportion of cleaved embryos inseminated with Y-sorted spermatozoa reached the blastocyst stage than cleaved embryos produced using
X-sorted spermatozoa. There was no significant interaction between sex and treatment for any embryokine. Rather response to treatment with IGF1, activin A and WNT7A was similar for female and male embryos.

\section{Gene expression}

As an additional test of whether sex affects response of the embryo to embryokines, the effect of IGF1 on gene expression of female and male blastocysts was assessed by evaluating expression using two separate 96-gene platforms. In total, expression of 127 genes was assessed (exclusive of housekeeping genes), including 53 genes for both experiments 1 and 2, 37 genes unique to experiments 1 and 37 genes unique for experiment 2 . Complete results are presented in Additional file 1 and results for genes affected by IGF1 or the interaction between IGF1 and sex are presented in Fig. 2.

Expression of 18 genes was significantly affected by sex $(P<0.05)$, with 12 genes $(A C T A 2, A K R 1 B 1, A M O T$, APOA1, ESRRB, HSD3B1, IFNT, MUC1, PPP2R3A, TGFB1, UBE2A, and XIAP) upregulated in females and 6 genes (CCL11, ELF5, INADL, MAPK13, ROBO, and SLIT2) downregulated in females (i.e., upregulated in males). Three of the 12 genes upregulated in female embryos were on the $\mathrm{X}$ chromosome (AMOT, UBE2A, and $X I A P)$ and none of the genes upregulated in males were located on the $\mathrm{Y}$ chromosome.

There were a total of 4 genes whose expression was significantly affected by the main effect of IGF1 with three genes upregulated (SNAI1, STAT4, and TNFSF8) and one gene downregulated (PRKAR2B). There were also three genes affected by the IGF1 by sex interaction (BMP4, CCR2, and DNMT1). For BMP4 and CCR2, IGF1 did not change expression in females but decreased expression in males. Note that expression of CCR2 was very low, particularly in females. For DNMT1, IGF1 increased expression in females but decreased expression in males.

\section{Discussion}

None of the three embryokines tested here affected developmental potential to the blastocyst stage of the bovine embryo in a sex-specific manner. In this regard, these molecules differ from another important embryokine, CSF2. Female and male embryos respond differently to CSF2 as revealed by differences in gene expression at the morula stage [15], competence to develop to the blastocyst stage [15], and elongation of the trophoblast at day 15 of development [24]. Thus, despite differences between female and male embryos at the transcriptome level as early as the morula and blastocyst stages (present results and earlier studies $[23,26])$, our data indicate that sex-dependent differences in regulation of developmental competence of embryos by maternal regulatory signals is 


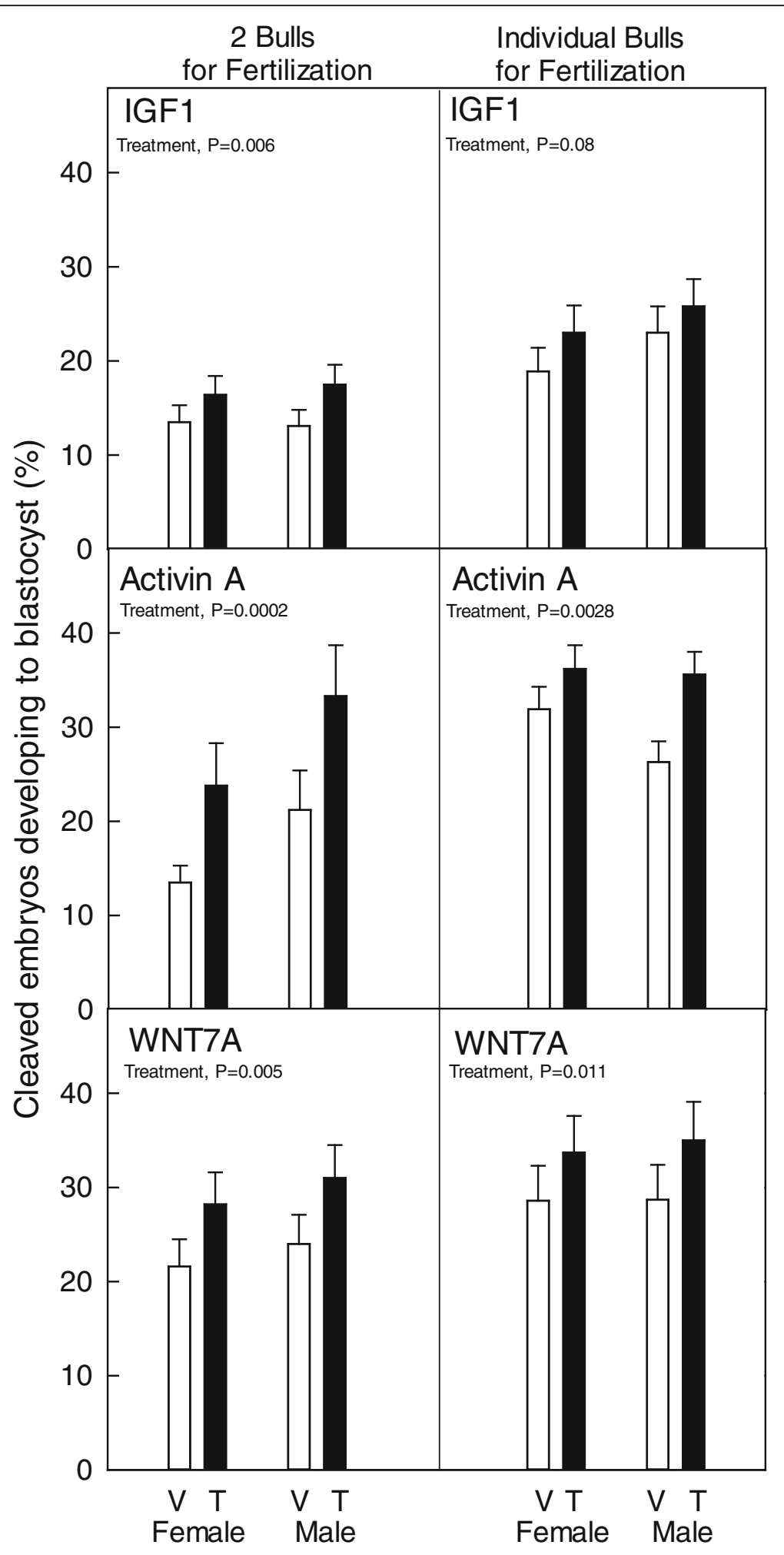

Fig. 1 Effect of exposure of female and male embryos to embryokines ( $T$ ) or vehicle $(V)$ from Day 5 to Day 7 after insemination on the ability of cleaved embryos to develop to the blastocyst stage. Data are the least-squares means \pm SEM. Significant effects are indicated in each panel 

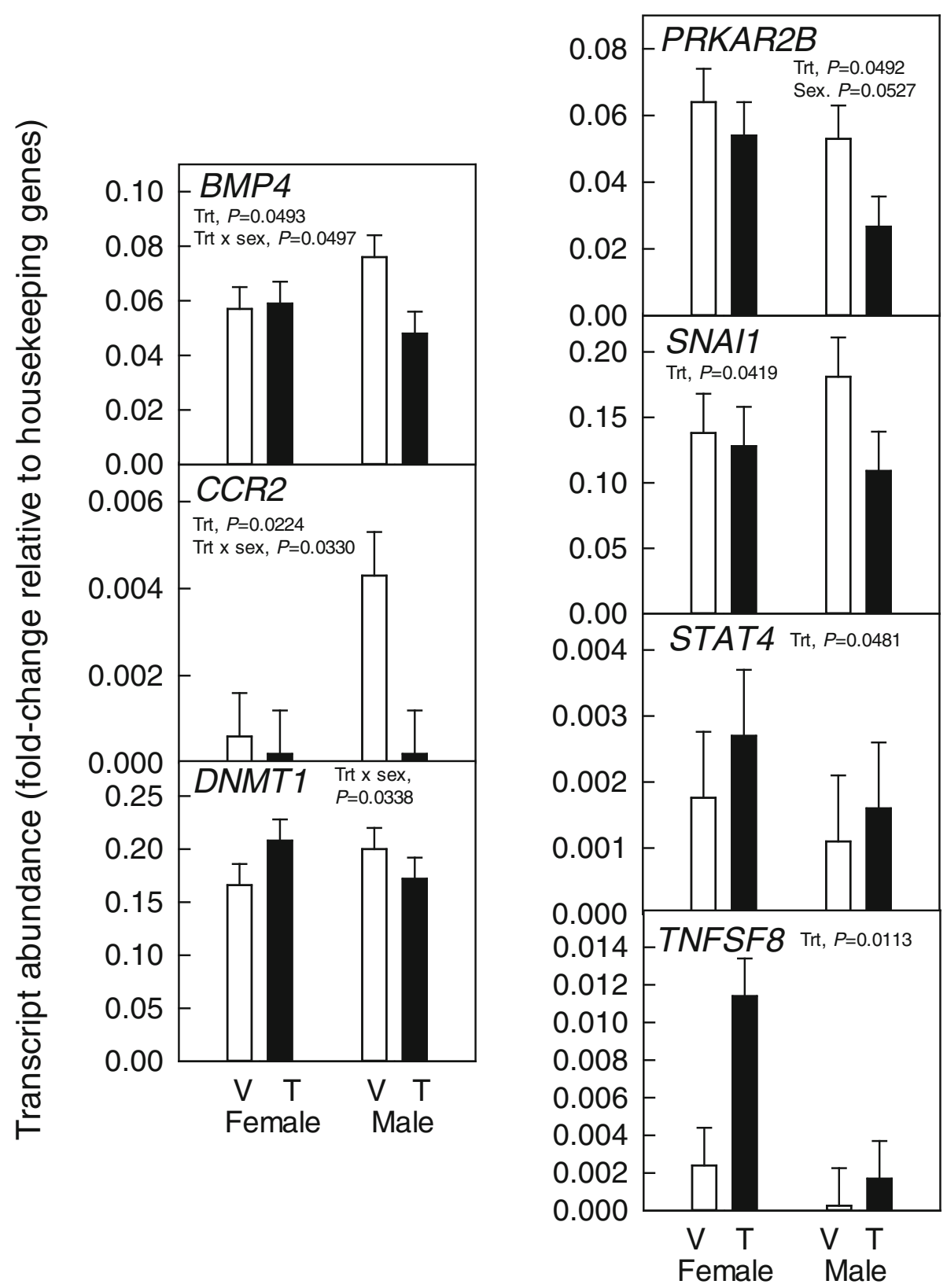

Fig. 2 Expression of genes in blastocysts that were affected by treatment with IGF1 (T) compared to vehicle ( $V$ ) from Day 5 to 7 after insemination or the interaction between IGF1 and sex. Data are least-squares means \pm SEM of fold change of level of expression relative to housekeeping genes

not a universal phenomenon. Rather, it is likely that sex regulates specific cell signaling pathways so that some embryokines regulate developmental competence in a sex-specific way where others do not. The fact that sex altered how IGF1 regulates gene expression is indicative that there could be sexual dimorphism in embryokine regulation of aspects of embryonic function other than ability to develop to the blastocyst stage.

The three embryokines tested here exert their actions by downstream pathways distinct from each other.
Activin A signals via SMAD proteins [27] and IGF1 activates the phosphatidylinositol 3' kinase/AKT pathway to block apoptosis [28] and the RAS/RAF/MAP kinase pathway to promote cell proliferation, growth and differentiation $[16,29]$. WNT7A can activate $\beta$-catenin-mediated WNT signaling [30] as well as the planar cell polarity pathway [31]. The cell signaling pathway for actions of CSF2 on the preimplantation embryo are not well understood because the early embryo does not express CSFRB [14], one of the two subunits of the CSF2 receptor. 
However, work with pig trophectoderm cells, in which CSFRB is also not expressed, indicate that CSF2 signals through phosphatidylinositol 3-kinase [32]. Since IGF1 prevents apoptosis through activation of this pathway [28] one cannot rule out that antiapoptotic actions of IGF1 are sexually-dimorphic. Indeed, there could be other aspects of development of the blastocyst not studied here, including downstream effects that occur much later in development, that could differ between female and male embryos. Embryokines like CSF2 [33, 34] and DKK1 [35] can act on the preimplantation embryo to affect fetal and postnatal phenotypes. Despite the lack of difference on development to blastocyst stage, the observation that expression of three genes was affected by the IGF1 by sex interaction is indicative that IGF1 might exert sex-dependent actions affecting other aspects of embryo function besides development to the blastocyst stage (e.g., apoptosis, allocation of cells into specific lineages, epigenetic regulation, etc.).

In general, there was no overall effect of sex on the proportion of embryos that developed to the blastocyst stage. Culture conditions, such as concentration of glucose [36] and presence of serum in the culture medium [37] can introduce a sex bias in development, which is another indication of differential susceptibility of female and male embryos to the environment. Culture conditions in the experiments here used low concentrations of glucose and the absence of serum [38].

The availability of sperm sorted based on the presence of an $\mathrm{X}$ or $\mathrm{Y}$ chromosome makes the bovine an easy-to-study species with respect to sexual dimorphism in development of the preimplantation embryo. Sex sorting of semen results in the desired sex in about 85-90\% of cases $[39,40]$. Sperm can be damaged by the sorting process $[41,42]$. It is possible, therefore, that mixing sires for fertilization, as was done in some of the current experiments, could result in the relative number of embryos produced by particular sires being different for $\mathrm{X}$-spermatozoa than Y-spermatozoa if damage did not occur equally for sperm of both type. To overcome this potential bias, all experiments were repeated using procedures where fertilization was performed with semen from a single sire only and the experiment replicated for several sires. Results were very similar whether multiple sires or single sires were used for fertilization, strengthening the idea that the embryokines tested affect male and female embryos similarly.

An important finding of these studies was the confirmation that IGF1, activin A and WNT7A enhance competence of the bovine embryo to develop to the blastocyst stage. Actions of IGF1 on the bovine embryo to increase development and block apoptosis are well described [16, 28, 43-45]. One of the few genes regulated by IGF1 in the present experiment was TNFSF8, which was upregulated by IGF1. Overexpression of CD30, the protein encoded by TNFSF8, has an anti-apoptotic effect [46]. One consequence of IGF1 treatment is increased competence of the embryo to establish pregnancy after transfer to heat stressed females [47-49]. While embryotrophic effects of IGF1 have been well characterized, this are not the case for activin A and WNT7A. Here we confirm earlier findings that both activin $\mathrm{A}[13,50]$ and WNT7A [18] can increase the proportion of embryos that develop to the blastocyst stage.

\section{Conclusions}

None of the three embryokines tested herein (IGF1, activin A and WNT7A) affected potential of the embryo to develop to the blastocyst stage in a sex-specific manner. This leads to the conclusion that sex-dependent differences in regulation of developmental competence of embryos by maternal regulatory signals is not a general phenomenon. Sex altered how IGF1 regulates expression of specific genes, however, and such a result suggests that there could be sexual dimorphism in embryokine regulation of aspects of embryonic function other than ability to develop to the blastocyst stage. Further experimentation focused on endpoints such as apoptosis, cell lineage commitment, epigenome, and development after the blastocyst stage should be conducted to clarify the situation.

\section{Methods}

\section{Embryo production}

Embryos were produced in vitro using oocytes harvested from ovaries recovered from a local abattoir and either $\mathrm{X}$ - or Y-sorted spermatozoa from Angus, Holstein or Simmental sires that were either purchased from ABS Global (De Forest, WI, USA) or Genex Cooperative (Shawano, WI, USA) or were donated by Sexing Technologies (Navasota, TX, USA). Only bulls in which both $\mathrm{X}$ - and Y-sorted spermatozoa were available were selected. The oocyte maturation medium was either a modified Tissue Culture Medium 199 [38] or, for experiments with WNT7A, a commercial collection medium called BO-IVM (IVF-Bioscience, Falmouth, Cornwall, UK). Media for fertilization and embryo culture were as described previously [38] except that fertilization medium contained $0.2 \%(w / v)$ amikacin sulfate (Sigma-Aldrich, St. Louis, MO, USA).

Procedures for in vitro oocyte maturation, in vitro fertilization, and embryo culture were as described previously $[15,26,38]$. Briefly, groups of 10 cumulus-oocyte complexes (COC) in $50 \mu \mathrm{L}$ microdrops of oocyte maturation medium covered with mineral oil (Sigma-Aldrich, St. Louis, MO, USA) were matured for $22-24$ h at $38.5^{\circ}$ $\mathrm{C}$ and $5 \%(\mathrm{v} / \mathrm{v}) \mathrm{CO}_{2}$ in a humidified atmosphere. Groups of 30 matured COC were placed in $60 \mu \mathrm{l}$ microdrops of IVF-TALP overlaid with mineral oil and mixed with 
$3.5 \mu \mathrm{l}$ penicillamine-hypotaurine-epinephrine and $20 \mu \mathrm{l}$ of sperm in IVF-TALP (final concentration $\sim 2 \times 10^{6} / \mathrm{ml}$ ) that had been purified using a Puresperm $40 / 80$ gradient (Nidacon International AB, Mölndal, Sweden). Depending on the experiments, sperm from a given replicate were either a mixture of two bulls or were from a single bull. In both types of experiments, the same bulls contributed both X-and Y-bearing spermatozoa for an individual replicate. Experiments were performed in several replicates; individual bulls or pairs of bulls differed between replicates. Fertilization was carried out for 16$18 \mathrm{~h}$ at $38.5{ }^{\circ} \mathrm{C}$ and a humidified atmosphere of $5 \%(v / v)$ $\mathrm{CO}_{2}$. Presumptive zygotes were washed in HEPES-TALP and then randomly placed in groups of 30 in $50 \mu \mathrm{l}$ microdrops of SOF-BE2 covered in mineral oil. Embryos were cultured at $38.5{ }^{\circ} \mathrm{C}$ in a humidified atmosphere of $5 \%(\mathrm{v} / \mathrm{v}) \mathrm{O}_{2}, 5 \%(\mathrm{v} / \mathrm{v}) \mathrm{CO}_{2}$ and the balance $\mathrm{N}_{2}$ or, for experiment $1,38.5{ }^{\circ} \mathrm{C}$ and $5 \%(\mathrm{v} / \mathrm{v}) \mathrm{CO}_{2}$ in humidified air. Treatments were added in a volume of $5 \mu \mathrm{l}$ at Day 5 after insemination (i.e, $120 \mathrm{~h}$ after insemination). Cleavage was assessed on day 3 after insemination and blastocyst development was evaluated $7.5 \mathrm{~d}$ after insemination.

\section{Embryokine treatments}

The procedure for treatment of embryos consisted of replacing $5 \mu \mathrm{l}$ culture medium in the microdrop with $5 \mu \mathrm{l}$ SOF-BE2 containing the embryokine at ten times the final concentration or the relevant vehicle. The final concentrations of embryokine tested were $100 \mathrm{ng} / \mathrm{ml}$ for IGF1, $1 \mathrm{nM}$ for activin A and $66 \mathrm{ng} / \mathrm{ml}$ for WNT7A. Treatments concentrations were chosen because they were effective at increasing the proportion of putative zygotes becoming blastocyst $[13,16,17]$. Human activin A (amino acid sequence identity with bovine $\beta_{\mathrm{A}}$ inhibin $=95 \%$ ) and recombinant human IGF1 (amino acid sequence identity with bovine IGF1 $=95 \%$ ) were obtained from Sigma-Aldrich, whereas recombinant human WNT7A (amino acid sequence identity with bovine WNT7A $=99 \%$ ) was purchased from eBioscience Inc. (San Diego, CA, USA). The vehicle was SOF-BE2 diluted 1:5 $(v / v)$ with water for IGF1, Dulbecco's phosphate-buffered saline (DPBS) with $0.1 \%(w / v)$ bovine serum albumin (BSA) for activin A and a mixture of $97 \%$ SOF-BE2 (v/v) and $3 \%(\mathrm{v} / \mathrm{v})$ of $10 \mathrm{mM}$ $\mathrm{NaPO}_{4}, 500 \mathrm{mM} \mathrm{NaCl}$ and $0.5 \%(\mathrm{w} / \mathrm{v})$ CHAPS diluted 1:100 (v/v) in DBPS-BSA for WNT7A.

\section{Experiments}

A total of six experiments (IGF1, experiments 1-2; activin A, experiments 3-4; WNT7A, experiments 5-6) were conducted. In each experiment, treatment (vehicle or embryokine) was applied to 1-2 drops of embryos produced with either X- or Y-sorted spermatozoa. Each experiment was replicated on several occasions, with bulls varying between replicates. Depending on the experiment, embryos in each replicate were produced by fertilization with spermatozoa pooled from two bulls (experiments 1, 3 and 5) or with sperm from a single bull (experiments 2,4 and 6). The total number of replicates for each experiment were 16 (10 bulls total) for experiment 1, 6 (10 bulls; experiment 2), 7 ( 6 bulls; experiment 3), 6 (8 bulls; experiment 4), 5 (8 bulls; experiment 5) and 7 (6 bulls total; experiment 6). In cases where the number of bulls is greater than the number of replicates, more than one bull was tested for some or all replicates.

\section{RNA extraction and gene expression}

Blastocysts exposed to IGF1 (experiments 1 and 2) were harvested to evaluate gene expression. Immediately after collection, blastocysts were washed three times in $50 \mu \mathrm{l}$ droplets of diethylpyrocarbonate (DEPC)-treated DPBS containing $0.1 \%(w / v)$ polyvinylpyrrolidone (PVP) and incubated with DEPC-treated DPBS-0.1\% (w/v) protease from Streptomyces griseus for zona pellucida removal. Zona-free blastocysts were washed three times in DPBS-PVP, and transferred into RNase/ DNase-free microcentrifuge tubes, and snap frozen in liquid nitrogen. A pool of 10 blastocysts was frozen as a biological replicate for gene expression analysis. There were a total of 44 pools of blastocysts analyzed ( 17 for experiment 1 and 27 for experiment 2).

Each pool of embryos was subjected to RNA extraction using the Qiagen RNeasy Micro kit (Qiagen; Valencia, CA, USA); DNase treatment was included as part of the protocol. Reverse transcription was performed using the High-Capacity cDNA Reverse Transcription Kit (Applied Biosystems; Foster City, CA, USA) following manufacturer's instructions.

The Fluidigm qPCR microfluidic device Biomark ${ }^{\mathrm{Tm}} \mathrm{HD}$ system was used to analyze gene expression using previously-described procedures [15]. The PCR primers were designed and synthesized by Fluidigm (Fluidigm Co., San Francisco, CA, USA). The set of primers for experiment 1 [51] and experiment 2 [52] were detailed elsewhere. After removing genes whose primers did not meet validation criteria, there were 37 genes analyzed for experiment 1 only, 37 genes analyzed for experiment 2 only and 55 genes that were analyzed for both experiments [two housekeeping genes, $A C T B$ and GAPDH, and 53 other genes). Genes included those involved in cellular differentiation, apoptosis, chemokine signaling and early embryonic development.

\section{Statistical analyses}

Effect of treatment on the proportion of cleaved embryos developing to the blastocyst stage was evaluated using Proc GLIMMIX of SAS for Windows, version 9.4 (SAS Institute Inc., Cary, NC, USA). Each embryo was considered an observation with binary response $(0=$ not 
developed to blastocyst, $1=$ developed to blastocyst) and analysis was performed by logistic regression fitting binary data distribution. The statistical model included the fixed effects of treatment, sex, treatment by sex interaction and random effect of replicate (experiments 1, 3 and 5). For experiments 2, 4, and 6 bull was also included in the model as a fixed effect.

Effect of treatment on gene expression was evaluated using Proc GLM of SAS with treatment, sex and treatment by sex interaction as fixed effects, and replicate as random effect. Gene expression was calculated relative to the geometric mean of two housekeeping genes $\left(A C T B\right.$ and GAPDH). The $\triangle \mathrm{Ct}$ and $2^{\Delta \mathrm{Ct}}$ was calculated for each gene.

For the 53 genes assessed in both experiments, data were combined and the model included treatment, sex, experiment, treatment by sex interaction, treatment by experiment interaction, sex by experiment interaction, and treatment by sex by experiment interaction as fixed effects, and replicate as random effect. When interactions were not significant, these terms were dropped from the model and the statistical analysis rerun. The response variable was $\Delta \mathrm{Ct}$ for both analyses. Results are presented as fold-change data relative to the geometric mean of the housekeeping genes (least-squares means \pm standard error of the mean).

\section{Additional file}

Additional file 1: Least-squares means of the fold-chage value for each gene examined, by treatment (control vs IGF1), sex (female vs male), and the interaction ( $P$-values from dCT analyses). Tab 1: Genes measured only in Experiment 1. Tab 2: Genes measured only in Experiment 2. Tab 3: Genes measured in both Experiments 1 \& 2. (XLS 95 kb)

\section{Abbreviations}

BSA: Bovine serum albumin; COC: Cumulus-oocyte complex; DEPC: Diethylpyrocarbonate; DPBS: Dulbecco's phosphate-buffered saline; PVP: Polyvinylpyrrolidone. Gene symbols (e.g., IGF1, WNT7A, etc.) are used as delineated at https://www.ncbi.nlm.nih.gov/gene/)

\section{Acknowledgements}

The authors thank Eddie Cummings, for ovary collection; owners and employees of Adena Meat Products L.P. (Fort McCoy, FL, USA), and Florida Beef Inc. (Zolfo Springs, FL, USA), for providing ovaries; the Miami Center for AIDS Research (CFAR) at the University of Miami Miller School of Medicine [funded by a grant (P30Al073961) from the National Institutes of Health] for performing qPCR; and Sexing Technologies (Navosota, TX, USA) for donation of semen.

\section{Funding}

Research was supported by funds from Agriculture and Food Research Initiative Competitive Grant 2011-67015-30688 from the USDA National Institute of Food and Agriculture and by funds from National Institutes of Health Grants R03 HD080855 and R01 HD088352.

\section{Availability of data and materials}

All data generated and analyzed during this study are included in this published article and the Additional file.

\section{Authors' contributions}

PT, GJ, KL, JM, VNP and PJH were involved in experimental design, data analysis and interpretation, and writing the paper. PT, GJ, KL, JM and VNP conducted the experiments. PJH oversaw the project. All authors read and approved the final manuscript.

\section{Ethics approval and consent to participate}

Not applicable.

\section{Consent for publication}

Not applicable.

Competing interests

The authors declare that they have no competing interests.

\section{Publisher's Note}

Springer Nature remains neutral with regard to jurisdictional claims in published maps and institutional affiliations.

\section{Author details}

${ }^{1}$ Department of Animal Sciences, D. H. Barron Reproductive and Perinatal Biology Research Program, and Genetics Institute, University of Florida, Gainesville, PO Box 110910, Gainesville, FL 32611-0910, USA. ²Department of Agriculture, University of Zululand, KwaDlangez Wa 3886, South Africa. ${ }^{3}$ Present Address: Department of Innovative Technology of Reproduction and Biotechnology of Farm Animals, Kazakh Scientific Research Institute of Animal Breeding and Forage Production, Almaty, Kazakhstan050035 / A10M6C4. ${ }^{4}$ Present address: Department of Animal and Poultry Sciences, Virginia Tech, Blacksburg, VA 24061, USA.

Received: 6 June 2018 Accepted: 18 July 2018

Published online: 28 July 2018

\section{References}

1. Gad A, Hoelker M, Besenfelder U, Havlicek V, Cinar U, Rings F, Held E, Dufort I, Sirard MA, Schellander K, Tesfaye D. Molecular mechanisms and pathways involved in bovine embryonic genome activation and their regulation by alternative in vivo and in vitro culture conditions. Biol Reprod. 2012:87:100.

2. Khurana NK, Niemann $\mathrm{H}$. Energy metabolism in preimplantation bovine embryos derived in vitro or in vivo. Biol Reprod. 2000;62:847-56.

3. Crosier AE, Farin PW, Dykstra MJ, Alexander JE, Farin CE. Ultrastructural morphometry of bovine compact morulae produced in vivo or in vitro. Biol Reprod. 2000;62:1459-65.

4. Sudano MJ, Santos VG, Tata A, Ferreira CR, Paschoal DM, Machado R, Buratini J, Eberlin MN, Landim-Alvarenga FD. Phosphatidylcholine and sphingomyelin profiles vary in Bos taurus indicus and Bos taurus taurus in vitro- and in vivo-produced blastocysts. Biol Reprod. 2012;87:130.

5. Boni R, Tosti E, Roviello S, Dale B. Intercellular communication in in vivoand in vitro-produced bovine embryos. Biol Reprod. 1999;61:1050-5.

6. Rizos D, Ward F, Duffy PAT, Boland MP, Lonergan P. Consequences of bovine oocyte maturation, fertilization or early embryo development in vitro versus in vivo: implications for blastocyst yield and blastocyst quality. Mol Reprod Dev. 2002;61:234-48.

7. Niemann H, Carnwath JW, Herrmann D, Wieczorek G, Lemme E, Lucas-Hahn A, Olek S. DNA methylation patterns reflect epigenetic reprogramming in bovine embryos. Cell Reprogram. 2010;12:33-42.

8. Ferraz PA, Burnley C, Karanja J, Viera-Neto A, Santos JE, Chebel RC, Galvão $\mathrm{KN}$. Factors affecting the success of a large embryo transfer program in Holstein cattle in a commercial herd in the southeast region of the United States. Theriogenology. 2016;86:1834-184.

9. Rexhaj E, von Arx R, Cerny D, Soria R, Bouillet E, Sartori C, Scherrer U, Rimoldi S. Assisted reproductive technologies-induced premature vascular ageing persists and evolves into arterial hypertension in adolescents. FASEB J. 2015;29:957-9.

10. Rexhaj E, Paoloni-Giacobino A, Rimoldi SF, Fuster DG, Anderegg M, Somm E, Bouillet E, Allemann Y, Sartori C, Scherrer U. Mice generated by in vitro fertilization exhibit vascular dysfunction and shortened life span. J Clin Invest. 2013;123:5052-60.

11. Donjacour A, Liu X, Lin W, Simbulan R, Rinaudo PF. In vitro fertilization affects growth and glucose metabolism in a sex-specific manner in an outbred mouse model. Biol Reprod. 2014;90:80. 
12. Siqueira LGB, Dikmen S, Ortega MS, Hansen PJ. Postnatal phenotype of dairy cows is altered by in vitro embryo production using reverse $X$-sorted semen. J Dairy Sci. 2017;100:5899-908.

13. Kannampuzha-Francis J, Tribulo P, Hansen PJ. Actions of activin A connective tissue growth factor, hepatocyte growth factor and teratocarcinoma-derived growth factor 1 on the development of the bovine preimplantation embryo. Reprod Fertil Dev. 2017;29:1329-39.

14. Dobbs KB, Khan FA, Sakatani M, Moss JI, Ozawa M, Ealy AD, Hansen PJ. Regulation of pluripotency of inner cell mass and growth and differentiation of trophectoderm of the bovine embryo by colony stimulating factor 2. Biol Reprod. 2013;89:141.

15. Siqueira LGB, Hansen PJ. Sex differences in response of the bovine embryo to colony-stimulating factor 2. Reproduction. 2016;152:645-54.

16. Bonilla AQ, Ozawa M, Hansen PJ. Timing and dependence upon mitogenactivated protein kinase signaling for pro-developmental actions of insulinlike growth factor 1 on the preimplantation bovine embryo. Growth Hormon IGF Res. 2011:21:107-11.

17. Paula-Lopes FF, de Moraes AA, Edwards JL, Justice JE, Hansen PJ. Regulation of preimplantation development of bovine embryos by interleukin-1 $\beta$. Biol Reprod. 1998:59:1406-12

18. Tribulo P, Caetano da Silva Leão B, Lehloenya KC, Hansen PJ. Consequences of endogenous and exogenous WNT signaling for development of the preimplantation bovine embryo. Biol Reprod. 2017;96:1129-41.

19. Hansen PJ, Dobbs KB, Denicol AC, Siqueira LGB. Sex and the preimplantation embryo: implications of sexual dimorphism in the preimplantation period for maternal programming of embryonic development. Cell Tissue Res. 2016;363:237-47.

20. Fleming TP, Watkins AJ, Sun C, Velazquez MA, Smyth NR, Eckert JJ. Do little embryos make big decisions? How maternal dietary protein restriction can permanently change an embryo's potential, affecting adult health. Reprod Fertil Dev. 2015;27:684-92.

21. Sinclair KD, Allegrucci C, Singh R, Gardner DS, Sebastian S, Bispham J, Thurston A, Huntley JF, Rees WD, Maloney CA, Lea RG. DNA methylation, insulin resistance, and blood pressure in offspring determined by maternal periconceptional B vitamin and methionine status. Proc Natl Acad Sci. 2007; 104:19351-6.

22. Dobbs KB, Rodriguez M, Sudano MJ, Ortega MS, Hansen PJ. Dynamics of DNA methylation during early development of the preimplantation bovine embryo. PLoS One. 2013;8:e66230.

23. Bermejo-Alvarez $\mathrm{P}$, Rizos D, Rath D, Lonergan P, Gutierrez-Adan A. Sex determines the expression level of one third of the actively expressed genes in bovine blastocysts. Proc Natl Acad Sci. 2010;107:3394-9.

24. Dobbs KB, Gagné D, Fournier E, Dufort I, Robert C, Block J, Sirard MA, Bonilla $L$, Ealy $A D$, Loureiro $B$, Hansen PJ. Sexual dimorphism in developmental programming of the bovine preimplantation embryo caused by colonystimulating factor 2. Biol Reprod. 2014;91:80.

25. Tríbulo P, Siqueira LGB, Oliveira LJ, Scheffler T, Hansen PJ. Identification of potential embryokines in the bovine reproductive tract. J Dairy Sci. 2018; 101:690-704.

26. Denicol AC, Leao BCS, Dobbs KB, Mingoti GZ, Hansen PJ. Influence of sex on basal and Dickkopf-1 regulated gene expression in the bovine morula. PLoS One. 2015;10:e0133587.

27. Miyazono K, Kusanagi K, Inoue H. Divergence and convergence of TGF- $\beta$ / BMP signaling. J Cell Physiol. 2001;187:265-76.

28. Jousan FD, Oliveira LJ, Hansen PJ. Short-term culture of in vitro produced bovine preimplantation embryos with insulin-like growth factor-I prevents heat shock-induced apoptosis through activation of the phosphatidylinositol 3-kinase/Akt pathway. Reprod Fertil Dev. 2008;75:681-8.

29. Chitnis MM, Yuen JSP, Protheroe AS, Pollak M, Macaulay VM. The type 1 insulin-like growth factor receptor pathway. Clin Cancer Res. 2008;14:6364-71.

30. Qu Q, Sun G, Murai K, Ye P, Li W, Asuelime G, Cheung YT, Shi Y. Wnt7a regulates multiple steps of neurogenesis. Mol Cell Biol. 2013;33:2551-9.

31. Le Grand F, Jones AE, Seale V, Scime A, Rudnicki MA. Wnt7a activates the planar cell polarity pathway to drive the symmetric expansion of satellite stem cells. Stem Cell. 2009:4:535-47.

32. Jeong W, Kim J, Bazer FW, Song G. Proliferation-stimulating effect of colony stimulating factor 2 on porcine trophectoderm cells is mediated by activation of phosphatidylinositol 3-kinase and activated protein kinase. PLoS One. 2014:9:1-9.
33. Kannampuzha-Francis J, Denicol AC, Loureiro B, Kaniyamattam K, Ortega MS, Hansen PJ. Exposure to colony stimulating factor 2 during preimplantation development increases postnatal growth in cattle. Mol Reprod Dev. 2015:82:892-7.

34. Siqueira LG, Tribulo P, Chen Z, Denicol AC, Ortega MS, Negrón-Pérez VM, Kannampuzha-Francis J, Pohler KG, Rivera RM, Hansen PJ. Colony-stimulating factor 2 acts from days 5 to 7 of development to modify programming of the bovine conceptus at day 86 of gestation. Biol Reprod. 2017;96:743-57.

35. Tríbulo P, Bernal Ballesteros BH, Ruiz A, Tríbulo A, Tríbulo RJ, Tríbulo HE, Bo GA, Hansen PJ. Consequences of exposure of embryos produced in vitro in a serum-containing medium to dickkopf-related protein 1 and colony stimulating factor 2 on blastocyst yield, pregnancy rate, and birth weight. J Anim Sci. 2017;95:4407-12.

36. Kimura K, Iwata $H$, Thompson JG. The effect of glucosamine concentration on the development and sex ratio of bovine embryos. Anim Reprod Sci. 2008;103:228-38.

37. Heras S, De Coninck DI, Van Poucke M, Goossens K, Pascottini OB, Van Nieuwerburgh F, Deforce D, De Sutter P, Leroy JL, Gutierrez-Adan A, Peelman L. Suboptimal culture conditions induce more deviations in gene expression in male than female bovine blastocysts. BMC Genomics. 2016;17:72.

38. Ortega MS, Wohlgemuth S, Tribulo P, Siqueira LG, Null DJ, Cole JB, Da Silva MV, Hansen PJ. A single nucleotide polymorphism in COQ9 affects mitochondrial and ovarian function and fertility in Holstein cows. Biol Reprod. 2017:96:652-63.

39. Welch GR, Waldbieser GC, Wall RJ, Johnson LA. Flow cytometric sperm sorting and PCR to confirm separation of $X$ - and $Y$ - chromosome bearing bovine sperm. Anim Biotechnol. 1995;6:131-9.

40. Welch GR, Johnson LA. Sex preselection: laboratory validation of the sperm sex ratio of flow sorted $X$-and $Y$-sperm by sort reanalysis for DNA. Theriogenology. 1999;52:1343-52.

41. Seidel GE, Garner DL. Current status of sexing mammalian spermatozoa. Reproduction. 2002;124:733-43.

42. Moce $E_{1}$ Graham JK, Schenk JL. Effect of sex-sorting on the ability of fresh and cryopreserved bull sperm to undergo an acrosome reaction. Theriogenology. 2006;66:929-36.

43. Moreira F, Hansen PJ, Badinga L, Thatcher WW. Effects of growth hormone and insulin-like growth factor-I on development of in vitro derived bovine embryos. Theriogenology. 2002;57:895-907.

44. Byrne AT, Southgate J, Brison DR, Leese HJ. Regulation of apoptosis in the bovine blastocyst by insulin and the insulin-like growth factor (IGF) superfamily. Mol Reprod Dev. 2002;62:489-95.

45. Lima PF, Oliveira MA, Santos MH, Reichenbach HD, Weppert M, Paula-Lopes FF, Neto CC, Goncalves PB. Effect of retinoids and growth factor on in vitro bovine embryos produced under chemically defined conditions. Anim Reprod Sci. 2006;95:184-92.

46. Al-Shamkhani A. The role of CD30 in the pathogenesis of haematopoietic malignancies. Curr Opin Pharmacol. 2004:4:355-9.

47. Block J, Drost M, Monson RL, Rutledge JJ, Rivera RM, Paula-Lopes FF, Ocon OM, Krininger CE, Liu J, Hansen PJ. Use of insulin-like growth factor-I during embryo culture and treatment of recipients with gonadotropin-releasing hormone to increase pregnancy rates following the transfer of in vitro-produced embryos to heat-stressed, lactating cows. J Anim Sci. 2003:81:1590-602

48. Block J, Hansen PJ. Interaction between season and culture with insulin-like growth factor-1 on survival of in vitro produced embryos following transfer to lactating dairy cows. Theriogenology. 2007;67:1518-29.

49. Loureiro B, Bonilla L, Block J, Fear JM, Bonilla AQ, Hansen PJ. Colonystimulating factor 2 (CSF-2) improves development and posttransfer survival of bovine embryos produced in vitro. Endocrinology. 2009;150:5046-54.

50. Park JE, Oh HJ, Hong SG, Jang G, Kim MK, Lee BC. Effects of activin A on the in vitro development and mRNA expression of bovine embryos cultured in chemically-defined two-step culture medium. Reprod Domest Anim. 2010; 45:585-93.

51. Negrón-Pérez MV, Zhang Y, Hansen PJ. Single-cell gene expression of the bovine blastocyst. Reproduction. 2017;154:627-44.

52. Negrón-Pérez MV, Hansen PJ. Role of yes-associated protein 1, angiomotin and mitogen activated kinase kinase $1 / 2$ in development of the bovine blastocyst. Biol Reprod. 2018;98:170-83. 